\title{
$\$$ Research Square

\section{Aspects Regarding the Redesign of a Component of the Vertical Lifting Module Used in Sustainable Production Management}

\section{Constantin Torcatoru ( $\sim$ constantin.torcatoru@unitbv.ro)}

Transilvania University of Brasov: Universitatea Transilvania din Brasov

\section{Dan Săvescu}

Transilvania University of Brasov: Universitatea Transilvania din Brasov

\section{Research Article}

Keywords: CAD, design for manufacturing and assembly, DFMA, tray, cost efficiency, manufacturing

Posted Date: December 17th, 2021

DOI: https://doi.org/10.21203/rs.3.rs-1157121/v1

License: (c) (1) This work is licensed under a Creative Commons Attribution 4.0 International License.

Read Full License 


\section{Abstract}

To remain competitive on the market with a developed product, it's very important to analyze the manufacturing costs and times, from the concept stage of the product. Design for manufacturing and assembly (DFMA) is one of the engineering methods that can be applied to reduce manufacturing costs and times, right from the design stage, without compromising product performance and reliability. The 3D modeling of the tray was made in Solidworks, and for the analysis of it's manufacture and assembly, the Boothroyd and Dewhurst principle and recommendations from the DFMA software were followed. This paper presents a case study for a subassembly called a tray, used in automatic vertical storage systems. For the redesigned model, substantial improvements were obtained, through cost reductions of $12 \%$ and an increase in design efficiency from 4.86 to 12.03. Product analysis using DFMA has proven to be a key point in the development of a product that meets engineers.

\section{Introduction}

The product development process is a well-known engineering activity that accompanies the product, from it's conception until it reaches the user. This process involves steps such as concept development, general design planning, detailed product design and, prototyping [17, 22, 28, 44]. While the first stages of the development process consist of iterative steps, which allow the designer to discover conceptual solutions (generating ideas), the last stages of the process are characterized by more practical activities, with recursive tasks.

Computer Aided Design (CAD) is considered the key tool of materialization in the design phase, and today, the CAD tool combines the initial capabilities for which it was designed, to create and display the product in a 3D visualization environment, with the benefits that derive from the integration of multidisciplinary design methodologies [21, 25].

Cost efficiency, ease of manufacture, as well as assembly/disassembly are some of the factors that govern modern products. Design for Manufacturing and Assembly (DFMA) is a well-established system that involves a product design technique used to minimize production and development costs from the design stage.

The use of the DFMA technique slows down the process in the product conceptualization stage, as additional activities for the DFMA will take place. According to Boothroyd, Dewhurst and, Knight, the extra time spent using DFMA techniques in the conceptualization stage is offset by the time savings when prototyping takes place [6]. DFMA is a practical design method, which allows the aspect of manufacturing and assembly production to be taken into account in advance [36].

Manufacturability describes the degree to which a product can be manufactured efficiently, addressing both overall feasibility and excessive cost [10]. 
DFA (Design for Assembly) is about simplifying the structure of the product because the total number of components in an assembly is an important point of design quality; fewer components result in a more efficient assembled product. The quality of the design refers to the value of the design brought to the clients' requirements. Design is the strong point of a product's quality, including systems and processes. The quality of the design can be improved by increasing the features and functionalities that can serve the needs and expectations of customers.

DFM (Design for Manufacturing) focuses on minimizing manufacturing complexity and exploring individual production costs. Reducing the number of components, by joining several parts or adopting different manufacturing processes, is a practice that can reduce assembly time $[8,11,13,16,26,30]$.

Implementing these two philosophies that DFMA, requires teamwork, we should participate designers, technologies and, operating personnel, to achieve the desired results.

Another important factor that must be taken into account when realizing the concept of a product is it's impact on the environment. Sustainable product design is one of the most effective approaches to achieving cleaner production, with an increased focus on the impact of products on the environment, as cleaner production has become a recent global concern for production $[2,15,37]$. In the early stages of sustainable design, it is a challenge to understand the requirements of each customer and to transform from these sustainable functional requirements to design parameters.

In addition, by implementing sustainability analysis, companies can be more competent and relevant in the contemporary market. Sustainability analysis allows the designer to develop an environmentally friendly product [14].

In the age of Industry 4.0, digital tools applied to production and manufacturing activities are a challenge for all manufacturing companies. Digital Twin (DT) technology is based on the integration of various "traditional" tools and aims to increase process performance. In DT, simulation modeling allows the construction of a digital copy of real processes, which is dynamically updated by data derived from intelligent objects. The use of DT in production activities is constantly increasing, as DTs are applied in different areas, from the design phase to the operational ones. Process safety and risk management remain a significant challenge for the process and production industries. Information Security (IS) aims to turn raw security data and information into meaningful and actionable information for security management, which can be considered an essential perspective for security management $[1,20,41]$.

Querying the Web of Science (WOS) database [47], globally, in the period 2000-2021, there are 952 bibliographic publications, on the subject of "design for manufacturing". Analyzing the distribution of publications by category, we found that most publications were in the category "Engineering Manufacturing" with 324 (34.03\%) publications, followed by "Design for Manufacturing" with 275 (28.88\%) publications, "Engineering Mechanical" with 183 (19.22\%) publications, "Industrial Engineering" with $121(12.71 \%)$ publications, followed by other categories that have less than 100 publications. 
Checking the distribution of publications by year, for the analyzed period, we found that the trend of this topic is upward, starting with 12 publications/year and reaching up to 70 publications/year, the most productive being the year 2018 (7.35\%). This shows us that the subject of "design for manufacturing" has been addressed more broadly in recent years, emphasizing the reduction of costs and manufacturing times, one of the requirements for maintaining a product on the market.

Of the total publications, $528(55.46 \%)$ represent proceedings paper, $413(43.38 \%)$ articles, and other publications, such as magazines, editorial materials, book chapters, etc.

The most productive region, with the most publications, was the USA with 387 (40.65\%) publications, followed by China, Germany and, France.

With the help of the VOSviewer tool, software for building and viewing bibliometric networks, the WOS database was completely downloaded and imported into the software, for the study of networks that includes journals, researchers, or individual publications and can be built based on citations, bibliographic links, co-citations or co-author relations [46].

Analyzing Figure 1, from the terms exposed with the greatest relevance, we found that "design for manufacturing" is at the top. We also identified new terms relevant to the analyzed field, such as "design", "concurrent engineering", "dfm", "manufacturability", "DFMA", starting with 2018 the analyzed field being approached to the area of "additive manufacturing", "modeling and simulation".

This paper addresses the DFMA method for redesigning the VLM Tray assembly:

- Analysis of the existing VLM Tray assembly, using DFA;

- Identifying the possibilities for improvement through DFM;

- Modifications to VLM Tray components to reduce the time and cost of manufacturing and assembly;

- Validation of optimizations through DFA and DFMA.

\section{Materials And Methods}

\subsection{The impact of DFMA analysis on products}

Engineers must understand very well the advantages and disadvantages of the materials selected for a product, the associated manufacturing process, and most importantly, the suppliers of materials, components, and subassemblies used in a product. Such an understanding will help define appropriate policies to reduce risks and help manage expectations [34].

Design for DFMA has great potential to minimize late technical changes, which impede the development of high-speed products and delay profit time. Therefore, it is often used to create technological devices for automatic assembly. The development of reconfigurable machines has become a new design approach, which not only includes existing approaches but should also include new design approaches. 
The success of a designed product can be measured by the capacity of the system that produces it. When designing a product, it is essential that the organizational capabilities of the technology and manufacturing system be considered as failing to do so, which can lead to non-manufacturable production models. A good design system ensures fast delivery of a quality, reliable and safe product. At the same time, making decisions about suppliers to improve production quality by reducing defects is an important step in designing a product $[19,29,32,33,39]$. Staged automation of digital electronic design and production can be a strategy for product quality assurance.

Early estimation of the costs of machined parts is difficult because it requires detailed process information that is not usually available during product design. Parametric methods address this issue by estimating the processing time of products. According to the "rule of 10" in quality management, especially in the early stages of design, decisions have a strong impact on the accuracy of the overall result $[3,35]$.

Dependencies between product development and material flow could lead to inefficient operations and excessive material use, both of which have a significant impact on manufacturing costs and time $[5,40]$.

Rima et al. (2015) used only a DFA approach, to analyze and calculate the current and design efficiency of refrigerator components. In their case study, some parts of the refrigerator were modified and redesigned using DFA instructions. For the new design, the minimum parts of the door assembly were reduced from 38 to 29 . From 69 components of the freezing chamber were reduced to 54 , and the components of the refrigeration system from 328 to 110 . The efficiency of the design of the evaporator unit with the fan was improved from $58-78 \%$, and the design efficiency of the refrigerator installation was improved from 38-63.9\% [30].

Engineers must understand very well the advantages and disadvantages of the materials selected for a product, the associated manufacturing process, and most importantly, the suppliers of materials, components, and subassemblies used in a product. Such an understanding will help define appropriate policies to reduce risks and help manage expectations [34].

The authors [24], propose a methodology that is validated by a redesign of a sheet metal industrial clock, in which the impact of sustainability is calculated from a comparison between an existing product and a new product. The implementation of the method in the case study demonstrates reductions of over $25 \%$ of product mass, energy consumed and $\mathrm{CO} 2$ footprint, and over $50 \%$ of theoretical assembly time and product complexity. The sustainability indicators of the proposed method are selected from the literature review and taking into account the attributes of sheet metal housing devices.

Mohammad et al. (2020), redesigned and improved a joystick, to achieve the goal of reducing the number of parts, handling and insertion time, and improving the design efficiency for a joystick. The result was an increase in design time by $21 \%$, and with a decrease in assembly time from 294.2 s to 232.44 s, they also achieved an improvement in design efficiency from 20.4-25.8\% [27]. 
Applying the DFA principle, to reduce the number of components in an entire product, a significant reduction in assembly costs and times was found. For example, Salikan achieved an improvement in assembly time by $18.68 \%$ and an increase in design efficiency by $8.33 \%$ for a subassembly of a lawnmower. Effendi also achieved a reduction in assembly time from $196.86 \mathrm{~s}$ to $69.84 \mathrm{~s}$, as well as an improvement in product efficiency by $5.2 \%[12,38]$.

\subsection{Vertical Lift Module automatic storage system}

Vertical Lift Module (VLM) automatic storage systems consist of a storage column in which small items are stored in pull-out trays. These trays are inserted and extracted by a powered device, which moves vertically between the shelves in front of and behind the column, to make available in front of the selector, the specific tray it needs to process it's pickup line. The moving device is guided by an automatic control system, which in some cases is also interfaced with a software system so that the correct order of the recovery trays is set. Such VLM solutions are an interesting combination of several advantages of other dynamic product retrieval systems, such as the use of vertical space $[6,9,18,23]$.

Before the COVID-19 pandemic, McKinsey estimated that up to $30 \%$ of jobs in the U.S. would be automated, and "automation will drive productivity and growth, but millions of people around the world will have to change jobs. or to update their skills" [43].

A few months after the outbreak, as COVID-19 forces an unprecedented number of workers to stay at home, most companies have the only choice to use automation to keep their business running [7]. Due to the acceleration triggered by COVID-19, Bain \& Company estimates that the number of companies expanding automation technologies will double in the next two years [4].

The product analyzed by the DFMA method is a tray similar to that of Figure 3 , a component that is part of an automatic vertical storage system called Vertical Lift Module (VLM). This tray has the role of storing various products - with low or relatively high weight - in an orderly manner, respecting certain storage and sorting criteria, defined in the computer of the VLM system [18].

Depending on the construction and design of the tray adopted, it can be more or less modular, so that the user can configure the division of the compartments according to the products to be stored, or for the products that will change during use. VLM system, without the need to replace this tray.

Figure 2, shows a diagram with the main elements of such a VLM system, which works based on a computer-controlled elevator, having the role of "collecting" the trays located on the two trays, arranged in front and behind the elevator, and brought to the working position, input and output (I/O) of the trays [31].

The purpose of the tray component analysis was to optimize it's modular construction, reducing manufacturing time and cost.

\subsection{Methodology}


Using the DFMA software, implemented by Boothroyd and their suggestions for optimizing the tray, 3D will be remodeled compared to the original model, the goal is to increase the DFA index, a recommendation addressed by as many engineers as possible lately.

The DFA index is a design efficiency that is calculated by dividing the processing time for an ideal product by the processing time for the actual product [42]. This ratio of ideal process time to actual process time is then expressed as a percentage using the following equation (1):

$$
D F A_{\text {Index }}=\frac{100 \cdot\left[T_{1}+T_{2} \cdot\left(N_{\min }-1\right)\right]}{T_{a}},
$$

1

Where:

$\mathrm{T}_{1}=$ the ideal assembly process time for handling and inserting the first necessary item in the product;

$T_{2}=$ the ideal assembly process time for handling and inserting each subsequent necessary item in the product;

$\mathrm{N}_{\text {min }}=$ the theoretical minimum item count;

$\mathrm{T}_{\mathrm{a}}=$ the actual assembly process time for the product.

$T_{1}$ and $T_{2}$ differ depending on the size and weight of the product, as well as the $180^{\circ}$ symmetry of the part for at least one of it's axes.

All the values mentioned above are calculated by the software based on the justification of the part entries made in the DFA software. The DFA index is calculated in the DFA software at the successful entries.

DFA index for Existing Tray VLM assembly $=4.86$

For improved product design, designers aim to maximize the DFA index.

\section{Generation Of New Concept}

For the 3D CAD modeling of this tray subassembly, the construction of the base of the tray was made more efficient, emphasizing it's closure at both ends, by welding, so that the resistance is increased, the manufacturing time and cost are reduced, compared to the tray. existence, which is closed at the ends by the non-removable assembly, with pop-rivets. Also, the modeling of the channels on the side of the base of the tray was followed, for the easy introduction of the sleepers. 
After several 3D models made and broader multicriteria analysis, we decided to further analyze the tray made of sheet metal, joined ends by welding, presented in Figure 4.

\subsection{New model 3D CAD for tray}

The modeling was done for a medium-sized tray, with a length $L_{a}=1600 \mathrm{~mm}$, a width $\mathrm{I}_{a}=600 \mathrm{~mm}$, and a height $h_{a}=150 \mathrm{~mm}$. The thickness of the base of the tray $\mathrm{g}=2 \mathrm{~mm}$. The beam was modeled with a thickness $\mathrm{g}=1.5 \mathrm{~mm}$.

For the mounting of the beam, it was adopted to make a single model, which will be mounted in the mirror. Having five subassemblies of beams, you will need ten beams. For dividers, a number of six pieces was taken into account, but depending on the needs of users, a larger number of dividers can be added later Figure 4.

To calculate more easily and quickly in the DFMA analysis the necessary material, for each subcomponent separately, a 2D drawing was made with their developments. Figure 5, shows the unfolding for the tray base, having the dimensions $L=1886 \mathrm{~mm}, \mathrm{I}=891 \mathrm{~mm}, \mathrm{~g}=2 \mathrm{~mm}$.

After modeling each subcomponent of the tray assembly, their assembly was performed in the Assembly module, from Solidworks and the mass properties of the assembly, necessary for DFMA analysis, were shown, shown in Figure 6.

We found that the new product has a mass $m=25.3 \mathrm{~kg}$, volume $V=3,241.3 \mathrm{~cm}^{3}$, and an area $A=3.2 \mathrm{~m}^{2}$, in Figure 6, finding the center of gravity and the moment of inertia.

\subsection{New product analysis using the DFMA method}

The 3D CAD model made in Solidworks, presented in the previous subchapter was imported into the DFMA software, with the step extension, later verifying the product from a dimensional and geometric point of view.

To have a sustainable impact on the construction of tools and devices necessary for the manufacture of products, as well as the use of existing technology and equipment, but also the amortization of their investments, we considered a batch of 50,000 trays/year. Given that a medium-sized VLM system contains approximately 20-30 trays, signing around $1500 \mathrm{VLM}$ units/year and taking into account the fact that these trays can be replaced if defects occur during use, the batch for which the DFMA analysis is performed is justified and realistic. 
Table 1

Components for the tray assembly and the manufacturing batch

\begin{tabular}{|lllll|}
\hline Assembly name & Components & Material & Quantity & U.M. \\
\hline Tray & Base tray & DC02 & 50,000 & pc \\
\cline { 2 - 5 } & Beam & DC02 & 500,000 & pc \\
\cline { 2 - 5 } & Divider & DC02 & 300,000 & pc \\
\hline
\end{tabular}

For the batch of 50,000 pieces, which will influence the costs of tools, devices, verifiers (TDVs)/piece, a semi-finished product purchased from DC02 sheet sheets was chosen, with dimensions close to that of the product, with low carbon content, with density $\rho=7.83 \mathrm{~g} / \mathrm{cm}^{3}$ and breaking strength $\sigma=330 \mathrm{MPa}$, which are found in Figure 7.

The manufacturing processes for this product were chosen from the software library, opting for cold pressing processing. Two presses of 400 tons and 300 tons were chosen for the operations of punching, stamping, and bending.

For the base of the tray, due to it's relatively large dimensions, separate processing processes were chosen, the semi-finished product being introduced manually from one stage to another. Choosing this type of processing, the operation of trimming the contour of the product, stamping and perforating the side channels, were performed on the same press, having a single punch with the respective punches and tools. In the second stage, bending the sides on another press, using another punch and mold.

To perform the welding operation, we opted for MIG welding with gas metal arc, with the help of a robot, setting the percentage of scrap, the number of welding cordon, their total length, the radius of the cordon, fixed costs with the robot, and related consumables.

Also, the working parameters were set for the other operations of laser marking, manual and air cleaning, degreasing, galvanizing, operations that can be found in Figure 7.

Aspects such as the role of each component as a whole, product handling, introduction of components in hard-to-reach places, adjustment of component placement, difficulties in viewing assembly, removal of assembly connectors where appropriate, component analysis were analyzed. from a security point of view, the use of TDVs for an ergonomic workstation.

For the other two products, the crossbar and the divider, similar steps were taken with those from the manufacture of the tray base product, with a batch of 500,000 pieces for the crossbar and 300,000 pieces for the divider, according to Table 1.

Figure 8 shows the structure of the products and operations required in the assembly stage of the product tray. After setting the dimensional, economic parameters and the time related to the assembly 
technologies, the suggestions recommended by DFMA were analyzed, subsequently making the related changes, so that the DFA index is as high as possible.

It was found that for the new design, in the stage of assembling the tray, the most time is lost in the assembly of the beam subassembly, which consists of two beams, assembled in the mirror and inserted on the side channels of the base of the welded tray.

\section{Results And Discussion}

Following the analysis of the two products, the existing tray assembled by pop-rivets and the new design assembled by welding, following the procedure and recommendations of the DFMA software for their redesign, an improvement was made on the design, time, process, and manufacturing cost, for the batch of 500,000 pieces, Table 2 , as follows:

- Reducing the cost of the manufacturing process by $4 \%$;

- Reducing the cost of the assembly process by $57 \%$;

- Decreasing the investment of TDVs by $44 \%$;

- Elimination of assembly operations by $64 \%$;

- Reduction of the total assembly time by $60 \%$;

- Increase of the DFA index, according to the equation (1), by $147 \%$, from 4.86 to 12.03 ; 
Table 2

Analysis Totals for Design for Assembly (DFA)

\begin{tabular}{|lllll|}
\hline Entries including repeats & Baseline - Old Product & New Product & \multicolumn{2}{l|}{ Difference } \\
\hline Parts meet minimum part criteria & 4 & 4 & 0 & $0 \%$ \\
\hline Parts are candidates for elimination & 33 & 13 & -20 & $-61 \%$ \\
\hline Analyzed subassemblies & 5 & 5 & 0 & $0 \%$ \\
\hline Separate assembly operations & 48 & 10 & -38 & $-79 \%$ \\
\hline Total entries & 90 & 32 & -58 & $-64 \%$ \\
\hline Assembly labor time, s & & & & \\
\hline Parts meet minimum part criteria & 77 & 77 & 0 & $0 \%$ \\
\hline Parts are candidates for elimination & 520 & 188 & -332 & $-64 \%$ \\
\hline Insertion of analyzed subassemblies & 70 & 70 & 0 & $0 \%$ \\
\hline Separate assembly operations & 459 & 120 & -339 & $-74 \%$ \\
\hline Total assembly labor time & 1125 & 454.78 & -670.6 & $-60 \%$ \\
\hline Design efficiency & & & & \\
\hline DFA Index & 4.86 & 12.03 & 7 & $147 \%$ \\
\hline
\end{tabular}

\section{(a) (b)}

Figure 9. Assembly time and cost of manufacturing: (a) total time of assembly/product; (b) total cost of manufacturing/product, including the cost of tools, manufacturing, and assembly.

Analyzing the two diagrams, from Figure 9, we found that the assembly time was improved by eliminating pop-rivet assembly operations and related manipulations, but also separate operations of rivet assembly, which required difficulties in inserting pop-rivets into the holes, as well as the positioning of the riveting tools. Thus, the assembly time was optimized by approximately $50 \%$, which for a batch of 50,000 trays means an efficiency of approximately $9305 \mathrm{~h}$. Of course, for the manufacture and assembly of the trays, there are several similar lines, for which time will be divided by the number of lines, results obtained in Table 2.

Also, the total costs/product for the manufacturing and assembly process were reduced by approximately $12 \%$, by $21.75 € /$ product, so that for the batch of analyzed products, it means a cost saving of $1,087,349 € /$ year, results obtained in Table 3 . 
Table 3

Analysis Totals for Design for Manufacture and Assembly (DFMA)

\begin{tabular}{|lllll|}
\hline Per product costs, $€$ & Baseline - Old Product & New Product & Difference & \\
\hline Assembly process & 15.8 & 6.78 & -9.03 & $-57 \%$ \\
\hline Manufacturing piece part & 146.67 & 141.08 & -5.59 & $-4 \%$ \\
\hline Total cost without tooling & 162.47 & 147.86 & -14.61 & $-9 \%$ \\
\hline Total tooling cost & 16.29 & 9.16 & -7.14 & $-44 \%$ \\
\hline Total cost & 178.77 & 157.02 & -21.75 & $-12 \%$ \\
\hline Total tooling investment, $€$ & & & & \\
\hline Assembly tools and fixtures & 20 & 20 & 0 & $0 \%$ \\
\hline Manufacturing tooling & 814672 & 457885 & -356787 & $-44 \%$ \\
\hline Total investment & 814692 & 457905 & -356787 & $-44 \%$ \\
\hline Production life data and weight & 50000 & & & \\
\hline Life volume & 8938297 & 50000 & 0 & $0 \%$ \\
\hline Total production life cost, $€$ & 42.97 & 7850948 & -1087349 & $-12 \%$ \\
\hline Total weight, kg & 43.32 & 0.35 & $1 \%$ \\
\hline
\end{tabular}

\section{Conclusions}

Considering the increasing requirements for automated systems, due to the social distance, given that a medium-sized VLM system contains approximately 20-30 trays, meaning around 1500 VLM units/year, and taking into account the fact that these trays can be replaced if defects occur during use, the analyzed batch of 50,000 trays/year is justified, realistic, having a sustainable impact and a quick depreciation investment.

The DFMA study was analyzed and successfully applied to the VLM Tray assembly, addressing both the aspects related to the assembly design and the assembly of this product. The basic issues of production and technology have been taken into account since the design stage.

The result of replacing the manufacturing process for the tray base, from the assembly with pop-rivets, to the assembly of the two ends by welding them, proved to be an optimized process, which reduced both the manufacturing and assembly cost and the execution times.

Manufacturing costs have been reduced, from $178.77 €$ /product to $157.02 € /$ product, which means improving the efficiency of the product by $12 \%$. There was a reduction in assembly costs of $57 \%$ and a 
decrease in assembly process time by $60 \%$. The design efficiency of the assembly was improved by $147 \%$, after a successful analysis with DFMA.

The implementation of the DFMA concept, by using software for such an analysis, in the case of new product development (NPD), can be an added value brought to the newly developed product. The results of the DFMA have proven to truly support competing engineering.

\section{Declarations}

Author Contributions: Conceptualization, C.T. and D.S.; methodology, D.S.; software, C.T.; validation, C.T. and D.S.; formal analysis, C.T.; investigation, C.T.; resources, C.T.; data curation, C.T.; writing-original draft preparation, C.T.; writing-review and editing, D.S.; visualization, C.T. and D.S.; supervision, D.S.; All authors have read and agreed to the published version of the manuscript.

Funding: This research received no external funding.

Conflicts of Interest: The authors declare no conflict of interest.

\section{References}

1. Agnusdei GP et al (2021)). https://doi.org/10.3390/app11062767.Is digital twin technology supporting safety management? A bibliometric and systematic review. https://doi.org/10.3390/app11062767

2. Antony KM, Arunkumar S (2020) : DFMA and Sustainability Analysis in Product Design. In: Journal of Physics: Conference Series. Institute of Physics Publishing https://doi.org/10.1088/1742$6596 / 1455 / 1 / 012028$

3. Armillotta A (2021) On the role of complexity in machining time estimation. J Intell Manuf. https://doi.org/10.1007/s10845-021-01741-y

4. BAIN\&COMPANY: Automation rapidly scales up across sectors, with coronavirus crisis likely to force acceleration, https://www.bain.com/about/media-center/press-releases/2020/automation-rapidlyscales-up-with-coronavirus-forcing-acceleration/, last accessed 2021/02/14

5. Battaïa 0 : Design for manufacturing and assembly/disassembly: joint design of products and production systems et al (2018) https://doi.org/10.1080/00207543.2018.1549795

6. Battini DMDUAL-TRAY VERTICAL LIFT MODULES FOR FAST ORDER PICKING

7. Chernysh Y, Roubík H (2020) International collaboration in the field of environmental protection: Trend analysis and covid-19 implications. Sustain 12:24, 1-18. https://doi.org/10.3390/su122410384

8. Chhim $P$ et al (2019) Product design and manufacturing process based ontology for manufacturing knowledge reuse. J Intell Manuf 30:2, 905-916. https://doi.org/10.1007/s10845-016-1290-2 
9. Daria B : Dual-tray vertical lift module for order picking: A performance and storage assignment preliminary study. Proc. Summer Sch. Fr. Turco. Industrial Systems Engineering, 85-90 et al (2015)

10. David M, Anderson (2014) : DESIGN for MANUFACTURABILITY. How to Use Concurrent Engineering to Rapidly Develop Low-Cost, High-Quality Products for Lean Production.

11. Dittmar H, DfMA? https://www.gmisolutions.com/blog/dfm-dfa-and-dfma, last accessed $2021 / 06 / 12$

12. Effendi MSM : Sustainability analysis and integration with DFMA and FEA: A case study of radio design. In: AIP Conference Proceedings. p. 020076 American Institute of Physics Inc et al (2021) https://doi.org/10.1063/5.0044549

13. Favi C : Design for Manufacturing and Assembly vs. Design to Cost: Toward a Multi-objective Approach for Decision-making Strategies during Conceptual Design of Complex Products. In: Procedia CIRP. pp. 275-280 Elsevier B.V et al (2016) https://doi.org/10.1016/j.procir.2016.04.190

14. Gebisa AW, Lemu HG (2017) Design for manufacturing to design for Additive Manufacturing: Analysis of implications for design optimality and product sustainability. Procedia Manuf 13:724731. https://doi.org/10.1016/j.promfg.2017.09.120

15. He B et al (2018) Sustainable design from functional domain to physical domain. J Clean Prod 197:1296-1306. https://doi.org/10.1016/j.jclepro.2018.06.249

16. Isanaka SP et al (2016) Design strategy for reducing manufacturing and assembly complexity of airbreathing Proton Exchange Membrane Fuel Cells (PEMFC). J Manuf Syst 38:165-171. https://doi.org/10.1016/j.jmsy.2015.10.004

17. Karl T, Ulrich, Steven D, Eppinger (2011) Product Design and Development. MCGraw-Hill Irwin, Ney Work, USA

18. Kolar D et aIDESIGN OF ORDER-PICKING SYSTEMS WITH VLM-S

19. Korshunov GI : Development strategy and process models for phased automation of design and digital manufacturing electronics. In: IOP Conference Series: Materials Science and Engineering. Institute of Physics Publishing et al (2018) https://doi.org/10.1088/1757-899X/327/2/022062

20. Lee $J$ et al (2019) Improving process safety: What roles for digitalization and industry 4.0? Process Saf. Environ Prot 132:325-339. https://doi.org/10.1016/j.psep.2019.10.021

21. Marconi $\mathrm{M}$ et al (2018) CAD feature recognition as a means to prevent ergonomics issues during manual assembly tasks. Comput Aided Des Appl 15:5, 734-746.

https://doi.org/10.1080/16864360.2018.1441240

22. Markus Dauksz (2014) O. torkelsson: A Methodology Study and Method Development.

23. Meller RD, Klote JF (2004) A throughput model for carousel/VLM pods. IIE Trans (Institute Ind Eng 36:8, 725-741. https://doi.org/10.1080/07408170490458472

24. Mesa $J$ et al (2018) A novel approach to include sustainability concepts in classical DFMA methodology for sheet metal enclosure devices. Res Eng Des 29:2, 227-244. https://doi.org/10.1007/s00163-017-0265-4 
25. Morbidoni A : CAD-integrated LCA tool: Comparison with dedicated LCA software and guidelines for the improvement. In: Glocalized Solutions for Sustainability in Manufacturing - Proceedings of the 18th CIRP International Conference on Life Cycle Engineering. pp. 569-574 Springer Science and Business Media, LLC et al (2011) https://doi.org/10.1007/978-3-642-19692-8_99

26. Narcisa VALTER (2019) : DESIGN PENTRU FABRICARE SI ASAMBLARE.

27. Nasyitah Mohammad N : Design for Manufacturing and Assembly (DFMA): Redesign of Joystick. In: IOP Conference Series: Materials Science and Engineering. IOP Publishing Ltd et al (2020) https://doi.org/10.1088/1757-899X/864/1/012212

28. Pahl $\mathrm{G}$ et al (2007) Engineering design: A systematic approach. Springer London. https://doi.org/10.1007/978-1-84628-319-2

29. Pita IM : Analyses and redesign of a technological device for automated assembly, using Design for Manufacturing and Assembly approach. In: IOP Conference Series: Materials Science and Engineering. Institute of Physics Publishing et al (2019) https://doi.org/10.1088/1757899X/564/1/012058

30. Rima S, DESIGN FOR ASSEMBLY: AN APPROACH TO INCREASE DESIGN EFFICIENCY OF ELECTRONICS HOME APPLIANCE (2016) :. DAAAM Int. Symp. Intell. Manuf. Autom. 877-882 https://doi.org/10.2507/26th.daaam.proceedings.122

31. Rosi B et al (2016) Simulation-based performance analysis of automated single-tray vertical lift module. Int J Simul Model 15:1, 97-108. https://doi.org/10.2507/IJSIMM15(1)8.328

32. Sibanda $V$ : Engineering design featuring the life cycle approach for reconfigurable machine tool. In: Procedia CIRP. pp. 948-953 Elsevier B.V et al (2019) https://doi.org/10.1016/j.procir.2019.04.174

33. El Souri $M$ : Integrating manufacturing knowledge with design process to improve quality in the aerospace industry. In: Procedia CIRP. pp. 374-379 Elsevier B.V et al (2019) https://doi.org/10.1016/j.procir.2019.04.179

34. Srivatsan TS (2009) Materials Enhanced Design: The Materials Engineering Perspective to Product Design and Manufacturing. Butterworth-Heinemann, Oxford. https://doi.org/10.1080/10426914.2012.689460

35. Steimer C, Aurich JC (2016) : Analysis of Information Interdependencies between Product Development and Manufacturing System Planning in Early Design Phases. In: Procedia CIRP. pp. 460-465 Elsevier B.V. https://doi.org/10.1016/j.procir.2016.04.134

36. Sudin MN et al (2016) Design Efficiency Analysis Towards Product Improvement for Eco-Friendly Using DFMA Method. Open Mech Eng J 10:1, 173-181. https://doi.org/10.2174/1874155x01610010173

37. Suresh $P$ et al (2016) Integration of DFE and DFMA for the sustainable development of an automotive component. Int J Sustain Eng 9:2, 107-118. https://doi.org/10.1080/19397038.2015.1096313

38. Salikan SM, N. : Design and Analysis of Grass Cutting Machine by Using DFMA Method. In: IOP Conference Series: Materials Science and Engineering. IOP Publishing Ltd et al (2020) 
https://doi.org/10.1088/1757-899X/864/1/012213

39. Thompson MK : Design for manufacturing and assembly key performance indicators to support high-speed product development. In: Procedia CIRP. pp. 114-119 Elsevier B.V et al (2018) https://doi.org/10.1016/j.procir.2018.02.005

40. Urban M, Manlig F (2018) : Development of product while considering material flow in a product's life. MM Sci. J. March, 1313-2318 (2018). https://doi.org/10.17973/MMSJ.2018_03_2017114

41. Wang B (2021) Safety intelligence as an essential perspective for safety management in the era of Safety 4.0: From a theoretical to a practical framework. Process Saf Environ Prot 148:189-199. https://doi.org/10.1016/j.psep.2020.10.008

42. DFMA® - Cutting Billions in Manufacturing Costs Since 1983 | Boothroyd Dewhurst, Inc., https://www.dfma.com/software/dfma.asp, last accessed 2021/04/01.

43. Logistics automation: Big opportunity, bigger uncertainty | McKinsey, https://www.mckinsey.com/industries/travel-logistics-and-infrastructure/our-insights/automation-inlogistics-big-opportunity-bigger-uncertainty\#, last accessed 2021/02/14

44. New Product Development - Enfinio, Inc, http://enfinio.com/new-product-development/, last accessed 2020/10/29.

45. Vertical Storage System, Storage Solutions | Modula, https://www.modula.eu/products/verticalsolutions/, last accessed 2021/04/01

46. VOSviewer - Visualizing scientific landscapes, https://www.vosviewer.com/, last accessed 2021/06/03.

47. Web of Science [v.5.35] -Web of Science Core Collection Basic Search

\section{Figures}




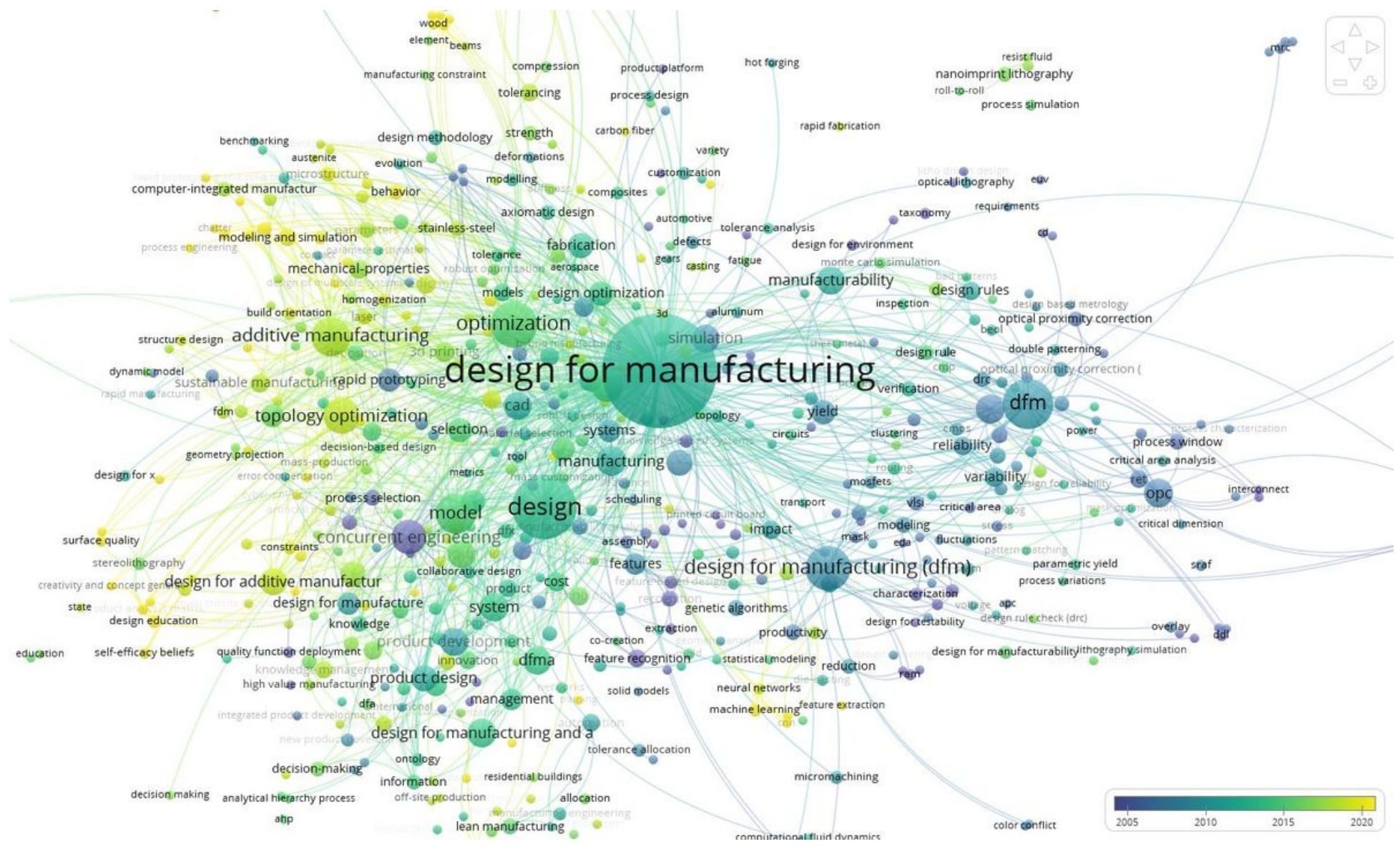

\section{Figure 1}

Map view descriptors for "design for manufacturing" use VOSviewer 

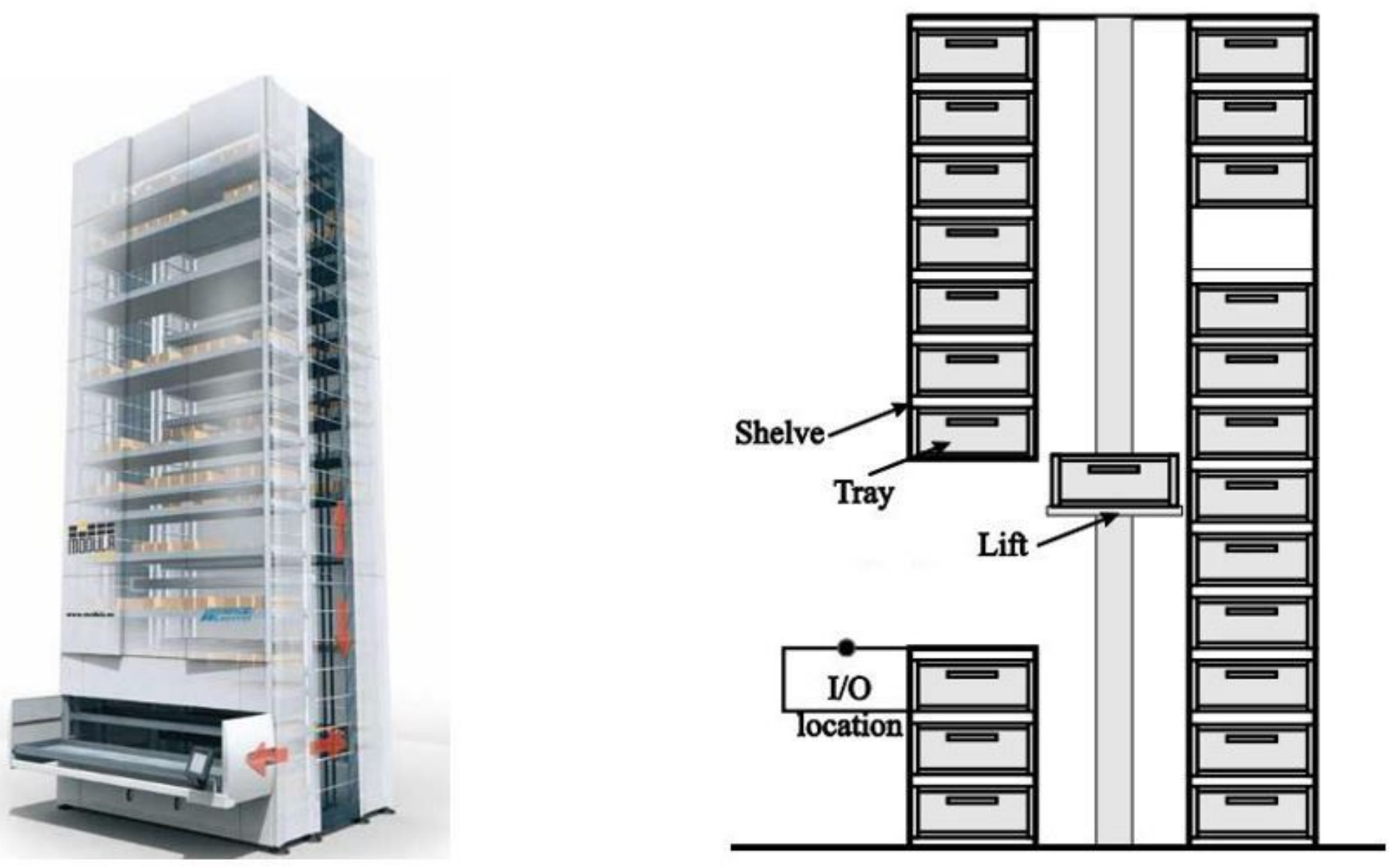

Figure 2

Structural diagram for a Vertical Lift Module system by Modula
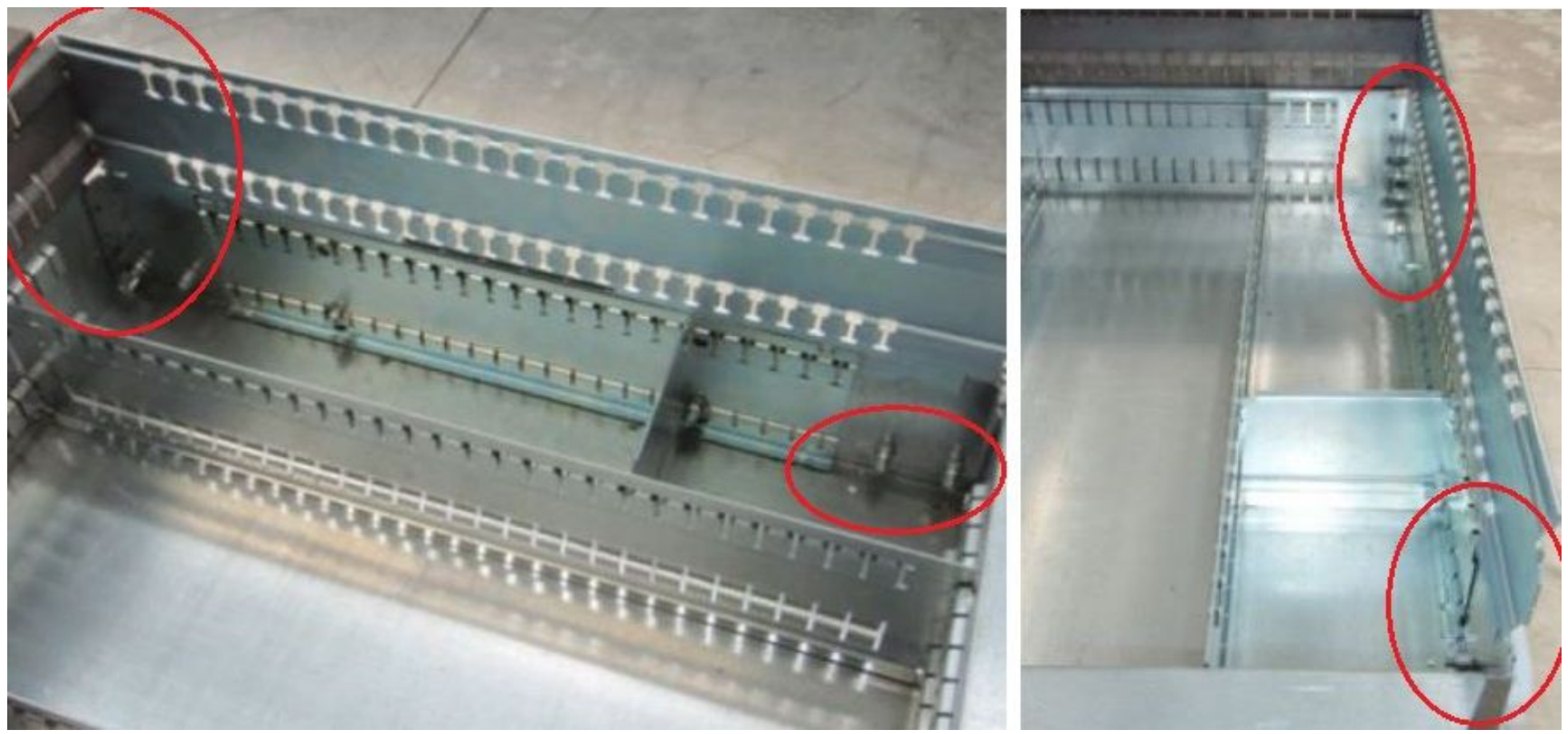

Figure 3 


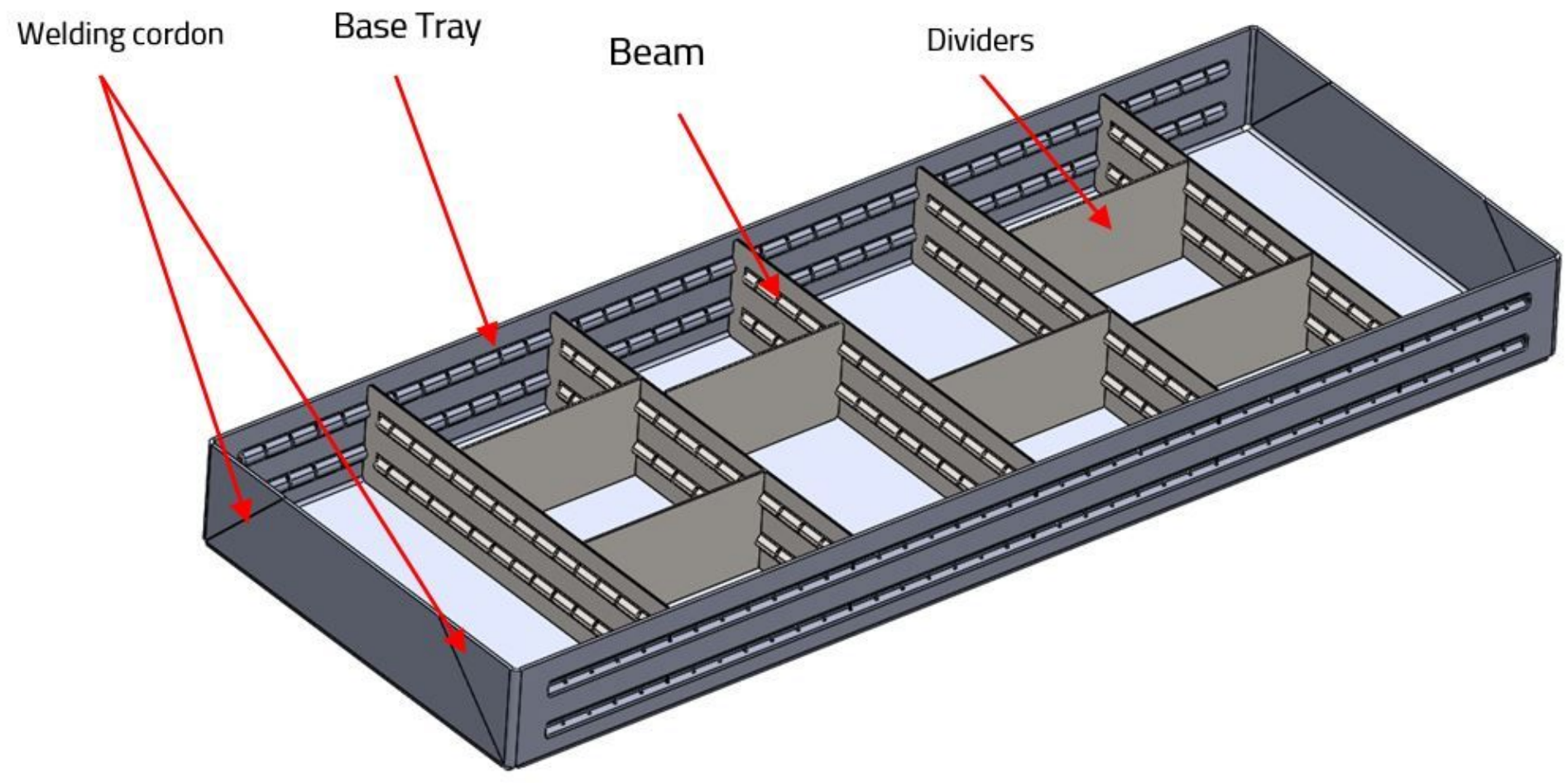

Figure 4

3D CAD model for the new product and components from Solidworks

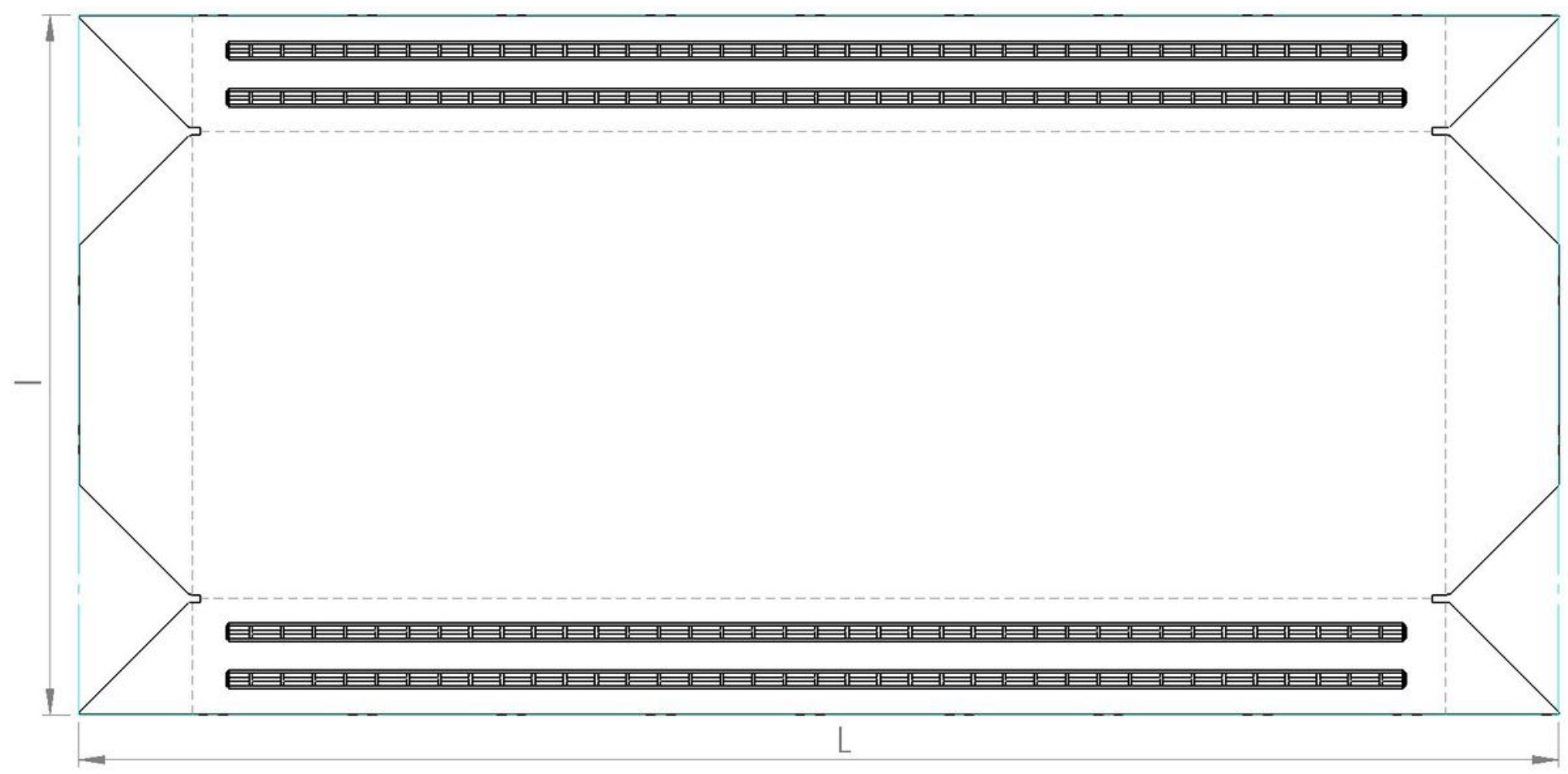




\section{Figure 5}

\section{D development for the tray base from Solidworks}

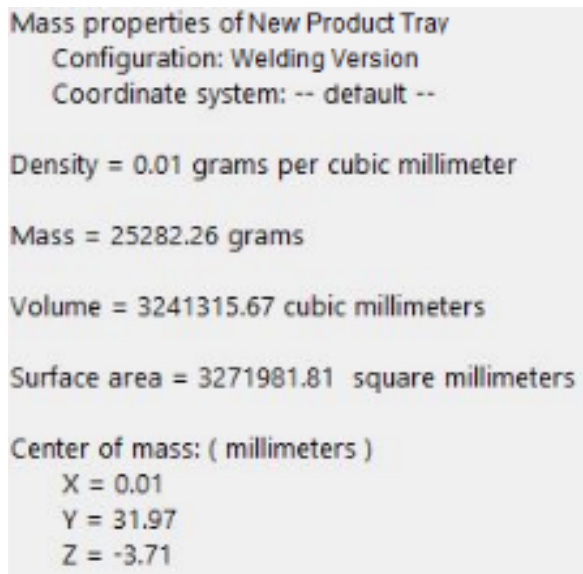

Principal axes of inertia and principal moments of inertia: ( grams * square millimeters ) Taken at the center of mass.
$\mathrm{Lx}=(0.00,0.00,1.00)$
$\mathrm{PX}=1257179984.25$
$\mathrm{ly}=(1.00,0.00,0.00)$
Py $=6573615188.27$
$\mathrm{z} z=(0.00,1.00,0.00)$
$\mathrm{Pz}=7724958977.53$

Moments of inertia: ( grams * square millimeters)

Taken at the center of mass and aligned with the output coordinate system.
$L x=6573615188.28$
Lxy $=9910.85$
$L x z=20398.75$
Lyx $=9910.85$
Lyy $=7724958944.77$
Lyz $=459667.46$
$\operatorname{LzX}=20398.75$
Lzy $=459667.46$
$L z Z=1257180017.00$

Moments of inertia: ( grams * square millimeters )

Taken at the output coordinate system.
lxox $=6599799420.05$
$\mathrm{lxy}=14249.85$
$|x|=19895.06$
lyx $=14249.85$
$y y=7725307098.09$
lyz $=-2539482.05$
IzX $=19895.06$
$\mathrm{Izy}=-2539482.05$
$\mathrm{IzZ}=1283016096.91$

\section{Figure 6}

Mass properties of new product tray from Solidworks 
4 Generic low carbon steel sheet metal part

4 Separate operations stamping process

4 Minster E2-400 Hevistamper (400 ton)

Load and unload part

Blank

4 Minster E2-300 Hevistamper (300 ton)

Load and unload part

Form bends

Robot MIG fillet weld

Laser mark

Hand deburr

Air nozzle clean

Wash/degrease part

Zinc plating

Inspect visually

\begin{tabular}{rrr|}
\hline Cost results, $€$ & & \\
& Previous & Calculate \\
material & 28.27 & 28.27 \\
setup & 0.05 & 0.05 \\
process & 27.21 & 27.21 \\
rejects & 0.84 & 0.84 \\
\hline piece part & 56.37 & 56.37 \\
tooling & 2.03 & 2.03 \\
\hline total & 58.40 & 58.40 \\
\hline Tooling investment & 101,599 & 101,599 \\
\hline & & \\
\hline
\end{tabular}

Part

Part name

Part number

Life volume

Manufacturing profiles

Current profile

CT Romania

Select a different profile...

Envelope shape
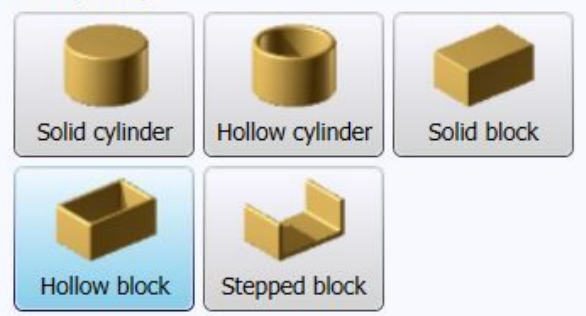

CAD view
Approximate envelope dimensions

CAD model is in millimeters $\checkmark$ Forming Principal

direction axis

$X$ axis, $\mathrm{mm} \quad 600.000 \quad \bigcirc$

$\mathrm{Y}$ axis, $\mathrm{mm}$

150.000

6

$(\bullet$

$\mathrm{Z}$ axis, $\mathrm{mm}$

1602.000

Average thickness, $\mathrm{mm}$

Notes<smiles>C1CCC1</smiles>

Thumbnail picture

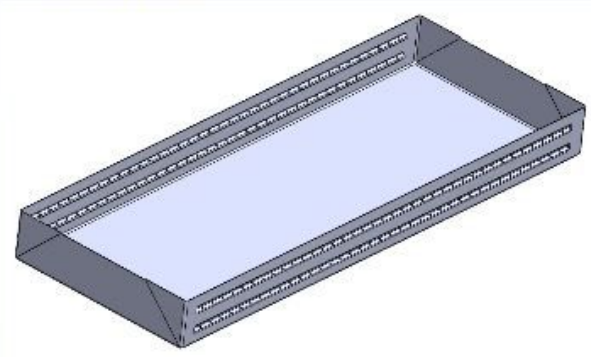

View full

\section{Figure 7}

Setting up the manufacturing process for the base tray 


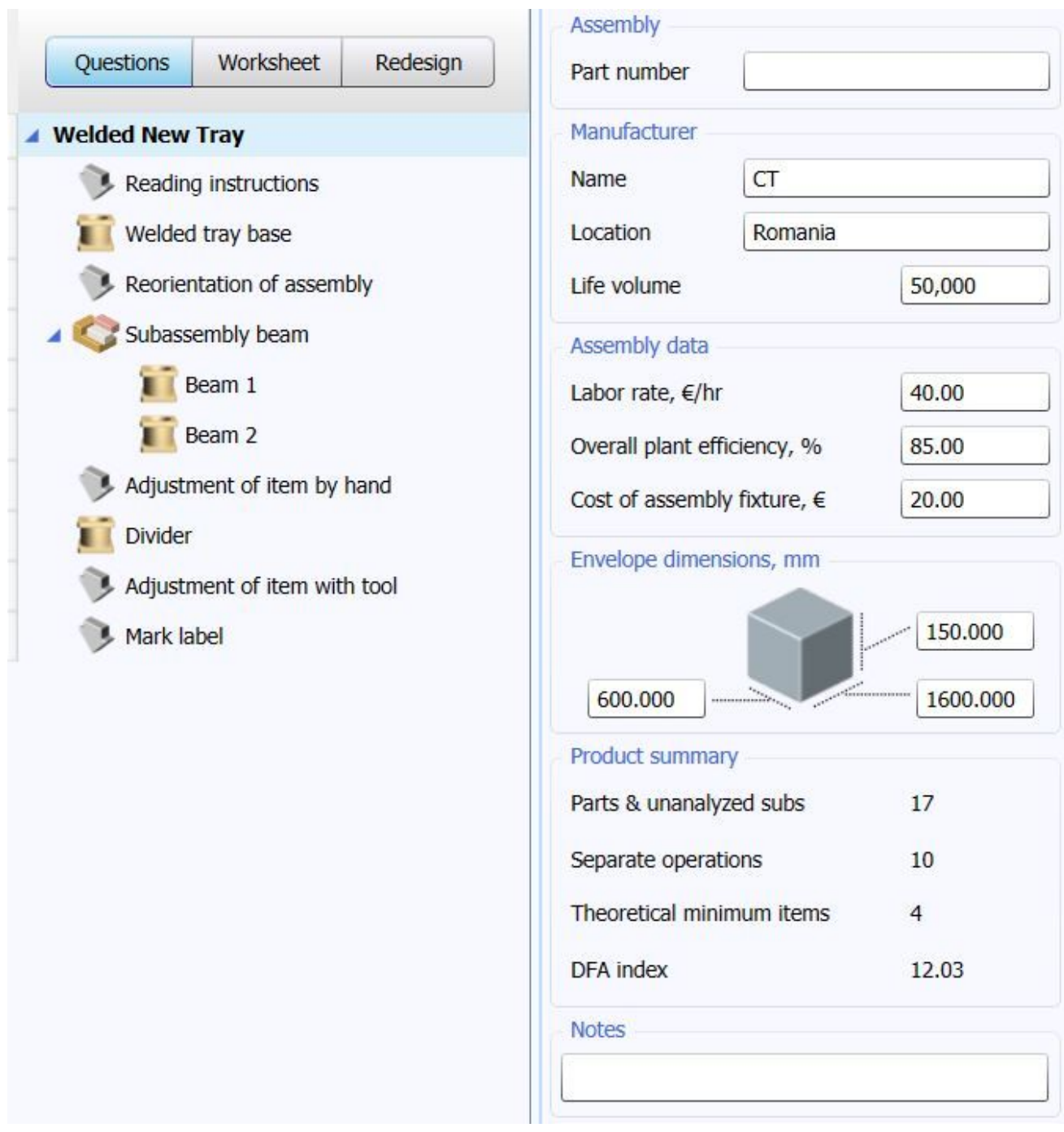

\section{Thumbnail picture}

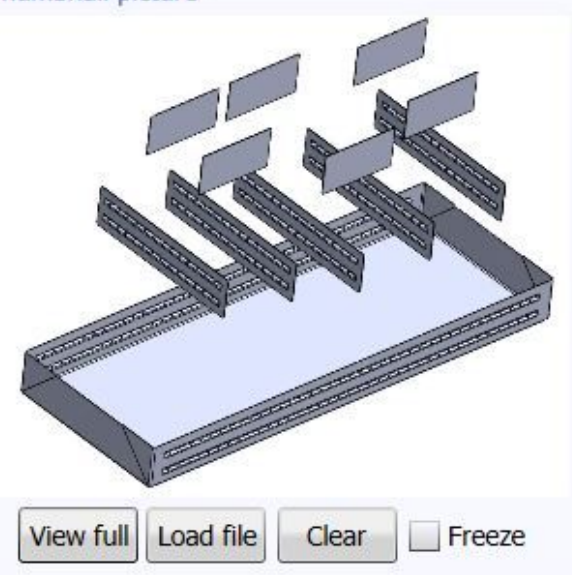

\section{Figure 8}

\section{Assembled structure diagram of the new product}

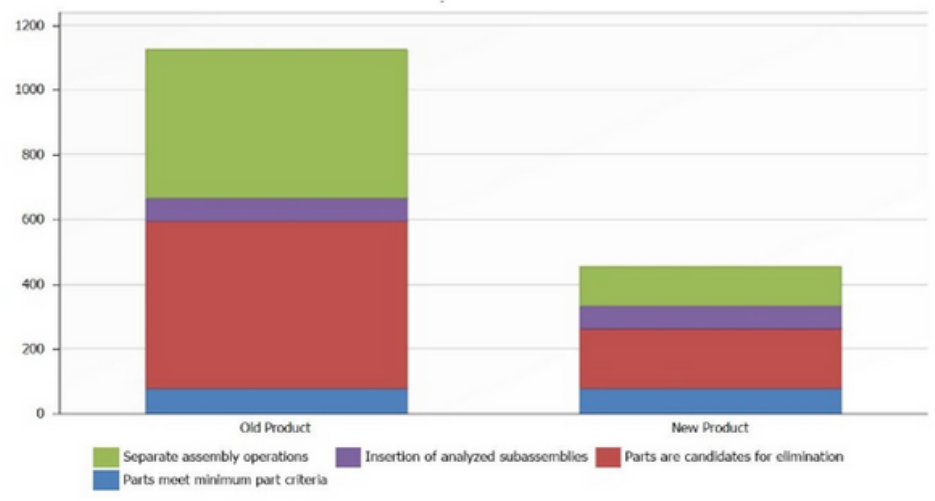

(a)

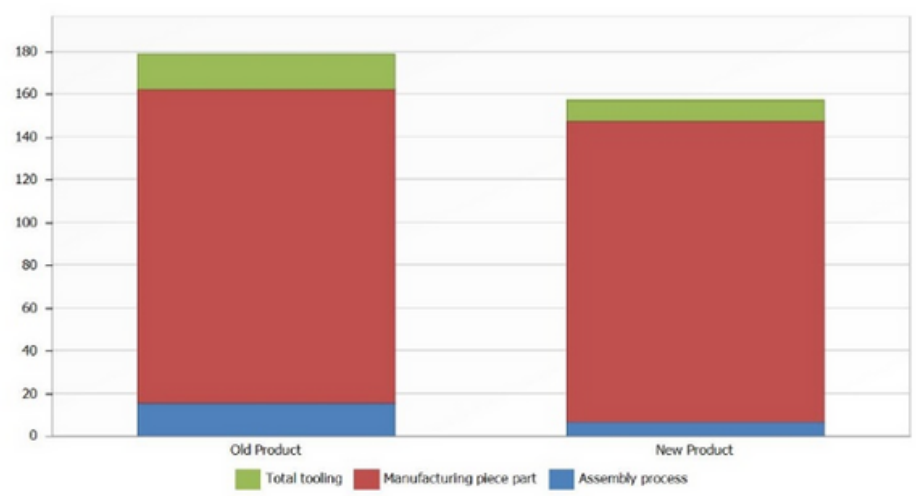

(b)

Figure 9 
Assembly time and cost of manufacturing: (a) total time of assembly/product; (b) total cost of manufacturing/product, including the cost of tools, manufacturing, and assembly. 